\title{
ARGAMASSAS DE TERRA VERSUS CONVENCIONAIS: AVALIAÇÃO DO DESEMPENHO AMBIENTAL CONSIDERANDO 0 CICLO DE VIDA
}

\section{EARTH VERSUS CONVENTIONAL MORTARS: ENVIRONMENTAL PERFORMANCE ASSESSMENT CONSIDERING THE LIFE CYCLE}

LUCAS ROSSE CALDAS, Dr. | UFRJ

RAYANE DE LIMA MOURA PAIVA, M.Sc.| UFRJ

ADRIANA PAIVA DE SOUZA MARTINS, Dra.| UFRJ

ROMILDO DIAS TOLEDO FILHO, Dr.| UFRJ

\begin{abstract}
RESUMO
Foram avaliados os potenciais impactos ambientais associados a diferentes argamassas de terra sem e com estabilizantes químicos (cal hidratada e cimento Portland) e tais impactos foram comparados com aqueles apresentados pelas argamassas convencionais de cimento, cal e areia. Foi utilizada a metodologia de Avaliação do Ciclo de Vida (ACV), com o escopo do berço ao túmulo. Foram avaliadas quatro categorias de dano: Mudanças Climáticas, Saúde Humana, Qualidade dos Ecossistemas e Depleção de Recursos foram avaliadas. Os ligantes químicos constituíram os insumos mais impactantes para a produção de argamassas de terra estabilizada, quando a ênfase foi o desempenho ambiental. A vida útil do revestimento e o transporte da terra influenciaram significativamente as categorias de Saúde Humana e Qualidade do Ecossistema. Os revestimentos de terra, mesmo quando estabilizados, podem ter ganhos ambientais de até $80 \%$ para a categoria de Mudanças Climáticas, caso tenham a mesma vida útil que revestimentos convencionais. Portanto, esses revestimentos baseados em terra crua podem constituir uma alternativa com grande potencial ambiental para mitigação dos impactos associados aos revestimentos comumente aplicados nas edificações. Ressalta-se, entretanto, a necessidade de serem adequadamente especificados na etapa de projeto, assim como de utilizarem, sempre que possível, a terra disponível localmente.
\end{abstract}

PALAVRAS CHAVE: Argamassas ecoeficientes; Terra; ACV; Vida útil; Transporte

\begin{abstract}
The potential environmental impacts of different earth mortar mixtures, with and without chemical stabilizers (hydrated lime and Portland cement), were evaluated and compared with conventional cement, lime, and sand mortars. We used the Life Cycle Assessment (LCA) methodology with a cradle-to-grave scope. Four damage categories were assessed: Climate Change, Human Health, Ecosystem Quality, and Resource Depletion. The chemical binders were the most environmentally impactful inputs for the stabilized earth mortars' production. The earth's coating, service life, and transportation were important mainly for the Human Health and Ecosystem Quality categories. Earth coatings, even when stabilized, can have up to $80 \%$ environmental gains for the Climate Change category if they have the same service life as conventional mortar coatings. Therefore, these coatings, based on raw earth, can be an alternative with the great environmental potential to mitigate the impacts of conventional coatings used in buildings. For this, they must be specified and used appropriately in the projects and as long as they use, preferably, locally available earth.
\end{abstract}

KEYWORDS: Eco-efficient mortars; Earth; LCA; Service life; Transportation 


\section{INTRODUÇÃO}

Nos últimos anos, a preocupação ambiental e a busca por um desenvolvimento mais sustentável têm impulsionado o setor de argamassas de revestimento no sentido de desenvolver produtos de baixo impacto ambiental, que possuam um ciclo de vida menos poluente que as argamassas convencionais, baseadas em cimento e/ou cal. De forma convergente, a normalização brasileira avançou em relação aos requisitos mínimos de desempenho para os materiais, componentes e sistemas construtivos, enfatizando a importância da seleção de materiais baseada nos resultados de inventários de ciclo de vida dos produtos e no menor potencial de danos causados ao meio ambiente (ABNT NBR 15575, 2013).

Dentre as matérias-primas mais ecoeficientes que podem ser empregadas de forma alternativa destaca-se a terra: recurso natural, não poluente e não tóxico, incombustível, com elevada disponibilidade, capaz de ser aplicado por mão de obra não especializada, com boas propriedades higrotérmicas e que pode ser reciclado ao final do ciclo de vida (TORGAL; EIRES; JALALI, 2009).

Desde a antiguidade as argamassas desempenham importantes funções nos sistemas de vedação das edificações, contribuindo para a estanqueidade, o isolamento termoacústico, a absorção de movimentações, a resistência ao fogo e aos impactos, e consequentemente proporcionando salubridade e adequado conforto ambiental aos usuários (CARASEK, 2010). O emprego de revestimentos externos à base de cal e terra e internos à base de terra pode ser observado nos sistemas construtivos vernaculares (FARIA, 2018). Entretanto esses sistemas foram progressivamente abandonados com o advento dos materiais industrializados, a partir de meados do século XIX (FARIA; HENRIQUES; RATO, 2008).

Atualmente, no Brasil, as argamassas de terra têm merecido atenção crescente tanto de pesquisadores quanto de profissionais da construção civil, haja vista as entidades, redes de pesquisa e os eventos especializados no tema, tais como Associação Brasileira de Materiais Não Convencionais (ABMTENC), rede PROTERRA, congressos Terra Brasil, respectivamente, dentre outros. No entanto, quando se pensa no uso de sistemas de revestimento de menor impacto ambiental, além da etapa de produção dos materiais, é crucial que seja considerado o desempenho dos mesmos ao longo de todo o ciclo de vida. Um item importante para uma especificação mais sustentável é o comportamento de durabilidade da argamassa. Se as argamassas apresentarem maior durabilidade, consequentemente terão uma vida útil maior e necessitarão de reposições menos frequentes ao longo da vida útil.
Revestimentos de terra podem ter uma menor vida útil quando comparados a revestimentos de argamassas de cimento ou mistas (cimento e cal), fazendo com que o ganho ambiental inicial seja perdido com a quantidade de reposições durante o ciclo de vida da edificação. Desta forma, é importante determinar a vida útil mínima para os revestimentos de terra, capaz de torná-los ambientalmente vantajosos quando comparados com os convencionais. Uma das ferramentas que pode ser utilizada para obtenção desse parâmetro é a metodologia de Avaliação do Ciclo de Vida (ACV).

A ACV pode ser definida como uma metodologia de avaliação de potenciais impactos ambientais de um produto, processo ou serviço ao longo de seu ciclo de vida, que pode envolver desde a extração dos materiais, o transporte, o uso até o fim de vida. Nessa metodologia são quantificados os principais dados ambientais de entrada e saída, possibilitando uma avaliação objetiva e meIhorando a tomada de decisão para uma gestão ambientalmente mais responsável (ABNT NBR ISO 14040, 2009). Nos últimos anos, a ACV tem sido frequentemente aplicada para a avaliação ambiental de produtos do setor da construção civil, sejam edificações, sistemas construtivos e materiais (ANAND; AMOR, 2017).

$O$ revestimento de terra, quando aplicado em uma vedação vertical, pode ser substituído de forma global, abrangendo todo o pano de alvenaria, ou de forma pontual, abrangendo pequenas regiões do pano. $O$ grau de intervenção vai depender de alguns fatores principais: composição e execução do revestimento, projeto arquitetônico (influência da cobertura e proteções), condições climáticas, preferência e condições (econômicas, sociais, etc.) dos usuários da edificação. O pior caso é a substituição total, conduzindo a maior consumo de material, e, consequentemente, impactos ambientais mais acentuados ao longo do ciclo de vida da edificação. Esses impactos ainda são majorados, de forma adversa, quando os materiais utilizados na reposição estão localizados em áreas distantes da edificação. Portanto, esses dois fatores, vida útil do revestimento e distância de transporte dos materiais, podem influenciar de forma significativa nos impactos ambientais do revestimento argamassado.

Neste contexto, o objetivo deste trabalho foi avaliar os potenciais impactos ambientais de argamassas e revestimentos internos e externos à base de terra, areia e estabilizados com cal e/ou cimento, que podem ser utilizados sobre blocos cerâmicos ou de concreto, e estimar os valores mínimos de vida útil que esses revestimentos precisam apresentar para obtenção de um melhor desempenho 
ambiental, quando comparados a revestimentos convencionais, de cimento e cal. Foi avaliado também como diferentes distâncias de transporte dos materiais utilizados na produção e como a reposição do revestimento influenciam nos impactos do ciclo de vida.

O presente trabalho inova por apresentar uma avaliação ambiental para argamassas de terra levando em consideração a realidade brasileira, não tendo sido encontrado nenhum estudo similar no país. Traz como contribuição a avaliação ambiental de um tipo de revestimento argamassado não convencional, porém com potencial de ser amplamente utilizado no Brasil, podendo atender tanto às demandas de novas edificações em áreas rurais e urbanas quanto às intervenções de restauro em edificações históricas.

\section{REFERENCIAL TEÓRICO}

A utilização da terra como material de construção é utilizada desde os primórdios da humanidade em diferentes sistemas construtivos. Dentro deste contexto as argamassas de terra podem ser utilizadas para diferentes finalidades tais como argamassas de assentamento, argamassas de reparação para paredes monolíticas e argamassas de revestimento interno e externo (VITOR et al., 2020). O interesse pelas argamassas de terra com e sem estabilização tem sido objeto de pesquisa e aplicação tanto em países desenvolvidos como Espanha, Itália, Portugal e França (MELIÀ et al., 2014; GARCÍA-VERA; LANZÓN, 2018; PERROT et al., 2018; SANTOS et al., 2019;) quanto em países em desenvolvimento como, por exemplo, Índia, Ghana, Botswana e Burkina Faso (NGOWI, 1997; HEMA et al., 2017; KULSHRESHTHA et al., 2020; DANSO; MANU, 2020). No Brasil, o emprego dessas argamassas destina-se principalmente para a restauração de centros históricos como Salvador - BA, São Luís - MA, Pirenópolis - GO, Diamantina - MG, Ouro Preto - MG e Olinda - PE (UNESCO, 2019) e para técnicas modernas e sustentáveis de construção (ATELIER O’R, 2019). Vitor et al. (2020) avaliaram a aderência e a aplicabilidade de diferentes argamassas de revestimento de terra em paredes de bahareque em uma construção na Universidade Federal de Santa Catarina (UFSC).

No ano de 2013 foram publicadas na Alemanha as primeiras normas específicas para argamassas de terra sem ligantes químicos: DIN 18946 (Earth masonry mortar Requirements, test and labelling) e DIN 18947 (Earth plasters - requirements, test and labelling). Portanto, em função da ausência de referências normativas específicas para argamassas de terra estabilizadas, observou-se que a maioria dos estudos internacionais utilizam as normas europeias EN 1015-11 (CEN, 1999) a EN 1015-12 (CEN, 2016) (Methods of test for mortar for masonry), enquanto os nacionais utilizam a NBR 13281 (ABNT, 2005), todas elaboradas para argamassas convencionais.

De acordo com Eires et al. (2014) e Faria (2016) as argamassas de terra estabilizadas quando comparadas com argamassas apenas de cal podem apresentar vantagens econômicas e ambientais porque consideram na sua formulação a fração argila como ligante.

A terra, na forma de material escavado ou na forma de resíduo de construção e demolição (RCD), tende a ser um recurso abundante, de baixo custo e disponível localmente, o que confere ao material credenciais econômicas e ambientais muito vantajosas. Essas argamassas de terra estabilizadas também possuem vantagens técnicas tais como trabalhabilidade, boas propriedades mecânicas e termohígricas, resistência à ação da água e erosão, retração controlada, redução da porosidade e da permeabilidade, além de serem naturalmente pigmentadas, o que pode ser aproveitado esteticamente (SANTOS et al., 2014).

A incorporação de areia contribui para a otimização do esqueleto granular e redução da retração por secagem (QUAGLIARINI; LENCI, 2010; PERROT et al., 2018). Na Figura 1 são observadas três regiões argamassadas, com misturas contendo areia (partes esquerda e superior direita) e apenas terra (parte inferior direita).

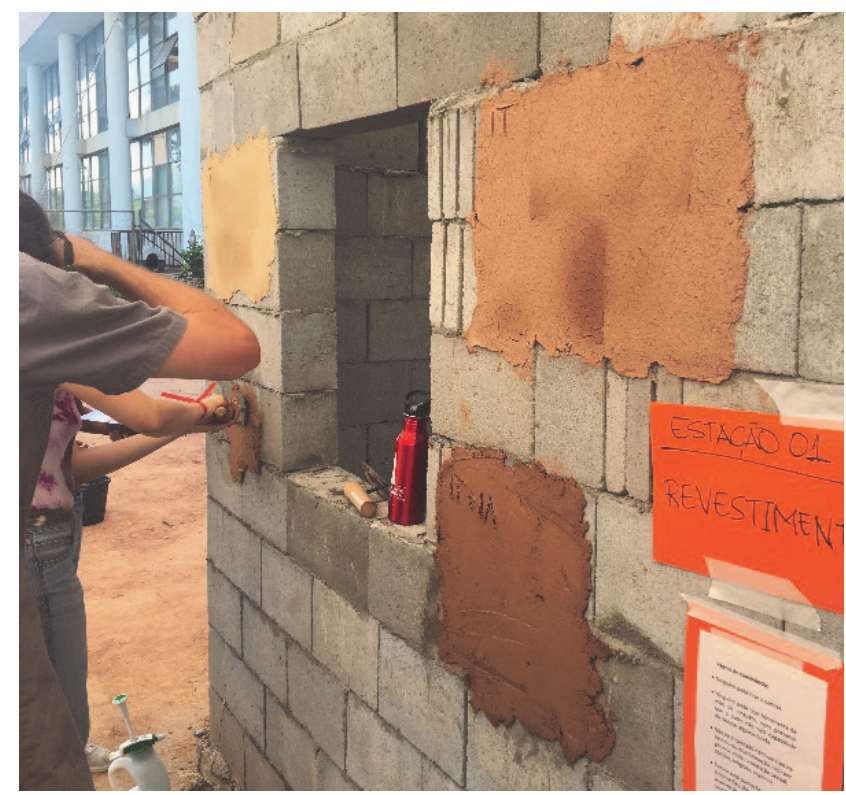

Figura 01 - Aplicação de revestimento de terra sobre alvenaria de blocos de concreto durante 0 evento Terra Brasil 2018, Rio de Janeiro Fonte: Autores (2018).

Existem poucas experiências sobre a aplicação da metodologia de ACV em materiais construtivos à base de terra, sendo que alguns merecem destaque, como é 
apresentado a seguir. Serrano et al. (2013) desenvolveram uma terra compactada estabilizada (SRE) visando à melhoria das propriedades térmicas através de materiais de mudança de fase (PCM) micro encapsulados. A incorporação de PCM na dosagem das misturas proporcionou otimização das propriedades térmicas, entretanto, os impactos ambientais aumentaram consideravelmente devido ao PCM micro encapsulado. Os autores concluíram que o uso desse material exige obrigatoriamente uma seleção adequada dos mesmos para diminuir os impactos ambientais em pesquisas futuras.

Melià et al. (2014) compararam através da ACV os impactos ambientais de argamassas de terra (ligante natural) com argamassas industriais convencionais (ligantes industrializados: cimento e/ou cal). Os resultados mostraram que o desempenho ambiental dos materiais de terra, cuja produção é baseada em processos simples que requerem quantidade relativamente pequena de energia, é substancialmente melhor do que o desempenho das argamassas convencionais. O maior componente de impacto é, para todas as argamassas, a energia consumida proveniente de combustíveis fósseis, responsável por uma faixa de 63\% a 85\% da energia incorporada total. No entanto, os maiores impactos das argamassas comerciais decorrem principalmente das emissões de $\mathrm{CO} 2$ durante o processo de calcinação na fabricação de cimento. Por outro lado, o transporte é muito importante, pelo menos em termos relativos, na determinação do impacto geral dos rebocos de terra. Isso destaca a importância de encontrar fontes locais de matérias-primas para não diminuir os benefícios ambientais dos produtos naturais de construção.

Christoforou et al. (2016) estudaram o ciclo de vida, por meio da ACV, da fabricação de tijolos de adobe onde diferentes cenários de produção foram analisados: (1) produção no local com solo localmente disponível e paIha ou serragem transportada, (2) produção no local com solo e palha / serragem transportados, e (3) produção industrial. Os resultados, em termos de energia incorporada e emissões de $\mathrm{CO} 2$, confirmaram que a minimização das necessidades de transporte e a utilização de recursos disponíveis localmente podem afetar significativamente a pegada ambiental de um sistema de produção de adobe. Eles também mostraram que o uso de serragem em vez de palha de trigo conduziu a um melhor desempenho ambiental do produto final. A energia e o carbono incorporados foram comparados com dados equivalentes referentes a outros materiais comuns de alvenaria, destacando a vantagem ecológica apresentada pelo material.
Ouellet-Plamondon e Habert (2016) avaliaram a pegada de carbono de um concreto de argila autoadensável e verificaram que o impacto Mudanças Climáticas desse material é inferior ao do concreto convencional produzido na Suíça.

Arrigoni et al. (2017) avaliaram a relevância de dois testes de durabilidade reconhecidos (erosão acelerada com a pulverização de água e perda de massa devido à escovação) e relacionaram os resultados à resistência e ao impacto ambiental de várias misturas de terra compactada. Os resultados demonstraram que é possível ter misturas duráveis de terra compactada, mesmo sem o uso de estabilizantes químicos com elevados impactos ambientais.

Marcelino-Sadaba et al. (2017) empregaram a ACV para avaliar tijolos cerâmicos queimados e não queimados e verificaram que o processo de queima é uma das etapas mais impactantes devido ao consumo de combustíveis. Sendo assim os tijolos não queimados possuem menores impactos ambientais. Por outro lado, possuem um desempenho mecânico muito inferior. Com base nos resultados obtidos os autores ressaltaram a necessidade de definir muito bem a aplicação de cada tipo de tijolo. Apontaram também que uma das maiores dificuldades da pesquisa foi obter dados de inventário que levassem em conta a variabilidade do solo.

Ben-Alon et al. (2019) avaliaram a demanda de energia e emissões de CO2-eq no ciclo de vida de um sistema de Cob com argamassa de terra, em comparação com uma parede de alvenaria de blocos de concreto e wood framing. O sistema de Cob apresentou ganhos consideráveis, de até $75 \%$, em relação ao consumo de energia, e de até $80 \%$ em termos de emissões. Fernandes et al. (2019) aplicaram a ACV para o estudo de terra compactada e blocos comprimidos de terra para o contexto de Portugal e verificaram redução nos impactos ambientais em torno de $50 \%$ quando os sistemas de terra são comparados com as paredes de tijolos cerâmicos e blocos de concreto.

Miranda e Yuba (2016) quantificaram as emissões de CO2 e energia incorporada de paredes de taipa de pilão no Brasil, utilizando a ACV modular (ACV-m). Eles compararam esse sistema com alvenaria de blocos cerâmicos, blocos de concreto e concreto moldado in loco. Os referidos autores concluíram que a taipa de pilão é mais vantajosa que os outros sistemas quando as microfibras de polipropileno não são consideradas no escopo do estudo.

Martins et al.. (2018) analisaram o desempenho ambiental de materiais compósitos constituídos por uma matriz de solo-cimento autoadensável reforçada com diferentes teores de fibras de sisal através da ACV. Foram avaliados os impactos ambientais de cada mistura 
produzida e os resultados foram normalizados em relação aos parâmetros de resistência mecânica (resistência à compressão e à tração) e de durabilidade (absorção capilar). Os resultados obtidos indicaram que a mistura com teor de fibras de 1,0\% apresentou o melhor desempenho em comparação com uma parede de blocos cerâmicos vazados revestida com argamassa convencional.

Com base na pesquisa realizada na literatura verificaram-se algumas conclusões comuns, entre elas: (1) o uso da terra como material de construção tende a ter um baixo impacto ambiental, por requerer processamento simples, exceto nos casos em que as distâncias de transporte são longas (que dependerá das características locais e geográficas de cada país); (2) o estabilizante químico (cal ou cimento) quando utilizado se mostra como o material mais impactante, principalmente para o impacto de potencial de aquecimento global; (3) é recomendado a substituição de parte desse estabilizante por materiais menos impactantes, como resíduos de outros processos industriais com propriedades pozolânicas; (4) os materiais à base de terra quando comparados com outros convencionais apresentam vantagens ambientais significativas. Dentre os materiais avaliados, os que mais têm recebido atenção são os painéis monolíticos de terra compactada e os tijolos/blocos, provavelmente devido ao fato de serem os elementos principais de uma vedação vertical. Especificamente sobre argamassas de revestimento de terra foi encontrado somente um estudo, o que mostra ser um campo com necessidade de ser mais explorado.

Foi verificado também na maioria dos trabalhos de ACV encontrados que a análise de sensibilidade de parâmetros importantes para materiais à base de terra, como por exemplo distância de transporte (principalmente da terra) e vida útil, não são investigados, o que evidencia a existência de uma lacuna de conhecimento que será explorada no presente estudo.

\section{MÉTODO}

\subsection{Composição das argamassas avaliadas}

Os traços (em volume) das argamassas convencionais adotadas no estudo foram 1:2:9 e 1:3:12 (cimento: cal: areia), obtidos do Sistema Nacional de Pesquisa de Custos e Índices da Construção Civil (SINAPI) (3), de códigos 88715 e 87295 , respectivamente. Foram avaliadas nove argamassas de terra, sendo três delas sem estabilizante (uso interno): 1:1,9; 1:2,4 e 1:3,8 (terra: areia) e seis estabilizadas, três com cal e três com cimento, para uso no lado externo. Os traços em massa das argamassas de terra foram desenvolvidos em laboratório a partir de traços obtidos na literatura, sendo: 1:0,05:3,75 (terra: cal: areia ou terra: cimento: areia); 1:0,10:3,70 (terra: cal: areia: água ou terra: cimento: areia) e 1:0,15:3,65 (terra: cal: areia: ou terra: cimento: areia). Para todos os traços foi adicionado um volume de água mínimo necessário à obtenção de boa trabalhabilidade e facilidade de aplicação manual.

\subsection{Avaliação do ciclo de vida (ACV)}

A ACV é dividida em quatro etapas, segundo a NBR ISO 14040 (ABNT, 2009): (1) Definição do objetivo, escopo e unidade funcional; (2) Inventário do ciclo de vida; (3) Avaliação do impacto do ciclo de vida; (4) Interpretação. Essas etapas serão descritas a seguir.

\subsubsection{Definição do Objetivo, escopo e Unidade Funcional}

O presente estudo de ACV tem os seguintes objetivos: (1) comparar diferentes misturas de argamassa de terra e convencionais (em $\mathrm{m}^{3}$ ); (2) avaliação para a vedação vertical, considerando a unidade funcional adotada; (3) e (4) Análises de sensibilidade relacionadas ao teor de estabilizante e distância de transporte do solo.

O escopo considerado consistiu nas etapas de produção dos materiais utilizados na argamassa (A1-A3), transporte até o canteiro de obras (A4), mistura e execução da argamassa (A5) e reposição das argamassas (de terra), considerando o transporte das novas argamassas e destinação final das antigas (B4). Foi também avaliada a etapa de fim de vida (C1-C4), como é verificado na Figura 2.

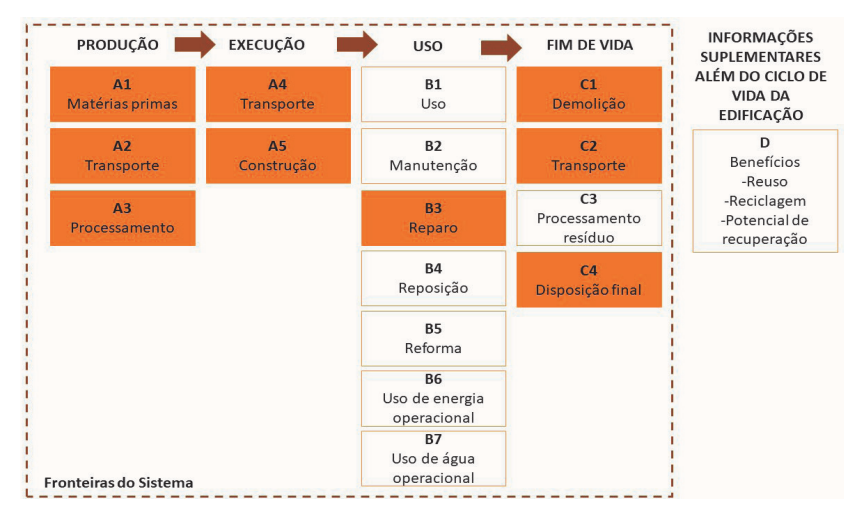

Figura 02 - considerado no estudo Escopo conforme organização da EN 15804 (CEN, 2012) Fonte: Autores (2020).

Foi utilizada como unidade funcional a "área de vedação vertical de $1 \mathrm{~m}^{2 \prime \prime}$ com revestimento argamassado em ambos os lados, com espessura de $30 \mathrm{~mm}$ de cada lado (interno e externo). Para o lado externo foi considerado revestimento com cal hidratada ou cimento 
Portland, terra e areia, enquanto que para o lado interno foi considerado revestimento de terra e areia de traço 1:2,4 (em massa). Para as argamassas convencionais foi considerada a aplicação em ambos os lados da alvenaria sobre uma camada de chapisco ( $5 \mathrm{~mm}$ de cada lado), sendo constituídas por uma camada única $(25 \mathrm{~mm}$ de cada lado). Foram contabilizados somente os revestimentos argamassados, sendo que o substrato da vedação vertical (exemplo: blocos cerâmicos) e revestimento final não foram incluídos.

As argamassas e os sistemas de revestimento avaliados apresentam diferentes formulações, resultando em desempenhos distintos. Entretanto essas diferenças tornam-se diluídas quando consideramos o sistema de vedação vertical de forma global, incluindo também os acabamentos após o revestimento de argamassa (pintura ou cerâmica). Essa abordagem já foi utilizada por outros estudos de ACV de revestimentos argamassados como o de Caldas et al. (2020b), e, portanto, pode ser considerado válido.

O estudo foi conduzido segundo a NBR ISO 14040 (ABNT, 2009) e NBR ISO 14044 (ABNT, 2009) e as recomendações da EN 15804 (CEN, 2012).

\subsubsection{Análise de inventário do ciclo de vida}

Foram avaliadas as argamassas em volume $\left(\mathrm{m}^{3}\right)$ para posterior avaliação na unidade funcional adotada, em $\mathrm{m}^{2}$. Para o inventário do ciclo de vida foram utilizados dados do banco de dados do Ecoinvent v. 3.3, com adaptação à realidade brasileira para o consumo de energia elétrica, transporte e para o tipo de cimento utilizado. Para o solo foi considerada a produção de argila, com extração mecanizada do material. No caso da areia britada, foram levadas em conta as operações para sua britagem. Foi utilizado o cimento Portland CP II-E32 (NBR 16.697 (ABNT, 2018)), considerando $5 \%$ de fíler e $10 \%$ de escória de alto forno. Para a cal hidratada (NBR 7175 (ABNT, 2003)) foram analisadas as etapas de produção e ensacamento. A água foi retirada da avaliação devido a sua pequena participação nos impactos ambientais (menor que $1 \%$ para as categorias de impacto avaliadas).

Para a etapa A4 foi adotado o transporte rodoviário com caminhões de carga de 10-32 toneladas, do tipo EURO 3, disponibilizados no Ecoinvent v.3.3. Para as distâncias de transporte foram adotados valores mínimos, intermediários e máximos, considerando uma variação dependendo dos insumos. Os valores adotados foram de 5, 50 e $200 \mathrm{~km}$ para a terra; 50, 200 e $500 \mathrm{~km}$ para cimento e cal; e 20, 50 e $100 \mathrm{~km}$ para areia, com base no estudo de Martins et al.
(2018). Essa variação foi calculada como desvio-padrão nos resultados encontrados. Na etapa $\mathrm{A} 5$ foi considerado que as argamassas são misturadas em betoneira de 400 L, com potência de $2 \mathrm{CV}$, retirado do banco de dados do SINAPI (2017) e que o trabalho de execução do revestimento é realizado manualmente, e, portanto, não sendo contabilizados os impactos ambientais para esse processo.

Para o fim de vida (C1-C4) das argamassas substituídas foram adotadas distâncias de transporte de 20, 40 e 60 km e destinação em aterro de resíduos inertes. Metodologia similar àquela empregada por Martins et al. (2018). A água foi desconsiderada da avaliação após ter sido verificado que sua participação é desprezível, menor que $1 \%$ (regra de corte adotada), para todas as categorias de impacto avaliadas. O resumo dos dados utilizados está apresentado na Tabela 1.

\begin{tabular}{|l|l|}
\hline Insumos & Datasets e fontes \\
\hline Terra & Clay \{RoW\}, Ecoinvent v. 3.3 \\
\hline $\begin{array}{l}\text { Cimento Portland } \\
\text { CPII-E32 }\end{array}$ & $\begin{array}{l}\text { Modelado pelos autores com base } \\
\text { Cement, Portland }\{\text { RoW\}, Blast furnace slag } \\
\{G L O\} \text { e Limestone, crushed, for mill }\{\text { RoW\}, } \\
\text { MME (2018) e Ecoinvent v. 3.3 }\end{array}$ \\
\hline Areia britada & $\begin{array}{l}\text { Sand }\{\text { RoW\}\} gravel and quarry operation, } \\
\text { Ecoinvent v. 3.3 }\end{array}$ \\
\hline Cal hidratada CHI & $\begin{array}{l}\text { Lime, hydrated, packed \{RoW\}, Ecoinvent } \\
\text { V. 3.3 }\end{array}$ \\
\hline $\begin{array}{l}\text { Eletricidade para } \\
\text { mistura }\end{array}$ & $\begin{array}{l}\text { Electricity, medium voltage }\{B R\}, \text { Ecoinvent } \\
\text { V. 3.3 }\end{array}$ \\
\hline $\begin{array}{l}\text { Transporte materiais } \\
\text { e resíduos }\end{array}$ & $\begin{array}{l}\text { Transport, freight, lorry 16-32 metric ton, } \\
\text { EURO3 \{GLO\}, Ecoin-vent v. 3.3 }\end{array}$ \\
\hline Aterro resíduos inertes & $\begin{array}{l}\text { Inert waste, for final disposal }\{\text { RoW\} }\} \text { treat- } \\
\text { ment of inert waste, inert material landfill, } \\
\text { Ecoinvent v. 3.3 }\end{array}$ \\
\hline
\end{tabular}

Tabela 01 - Insumos e atividades principais consideradas no inventário do ciclo de vida. Legenda Fonte: Autores (2020).

\subsubsection{Avaliação do impacto do ciclo de vida}

Foi utilizado o método de avaliação de impactos do ciclo de vida (AICV) IMPACT 2002+, considerando as seguintes categorias de impactos ambientais: (1) Mudanças Climáticas; (2) Saúde Humana; (3) Qualidade dos Ecossistemas; e (4) Depleção de Recursos. A modelagem foi realizada no software SimaPro v.8.5.

Nesse método, as categorias de impacto orientadas a problema ("midpoint") - potencial de aquecimento global, eutrofização, acidificação, depleção da camada de ozônio, etc. - são agrupados em quatro categorias de danos que podem ser considerados do tipo "endpoint", conforme Humbert et al. (2012). Esse método foi escolhido por reduzir as categorias de impacto avaliadas e facilitar a interpretação dos resultados. 


\subsubsection{Estimativa da quantidade de reposições dos revestimentos de argamassa de terra}

Para a etapa de reposição da argamassa de revestimento terra (B4), além da etapa de produção, transporte e aplicação dos materiais utilizados no novo revestimento, foi contabilizado o revestimento de terra antigo que é removido, transportado e enviado para destinação final, conforme recomendações da EN 15804 (CEN, 2012).

As atividades de manutenção, reparo e substituição (módulos de B2, B3, B4, respectivamente) envolvem tipicamente intervenções periódicas (isto é, substituições de materiais ou elementos) para assegurar o desempenho funcional da edificação. Essa avaliação calcula o número de vezes que uma tarefa ocorre durante a vida útil da construção, de acordo com a Equação 1, que é utilizada por Bowick (2018).

$$
N_{x}=\frac{\left(S-F_{x}\right)}{F_{x}}
$$

onde,

$\mathrm{N}_{\mathrm{x}}$ é o número de vezes que a tarefa $\mathrm{x}$ ocorre, considerando arredondamento; S é o período de estudo da referência do edifício (em anos); $F_{x}$ é a frequência da tarefa para a tarefa $\mathrm{x}$ (anos).

Posteriormente foi utilizada a Equação 2 para calcular o total de material substituído ao longo da vida útil da edificação.

onde,

$$
Q_{x, y}=N_{x} \times M_{y} \times P_{x, y}
$$

$\mathrm{Q}_{\mathrm{x}, \mathrm{y}}$ é a quantidade total de material y substituído devido à tarefa $\mathrm{x} ; \mathrm{N}_{\mathrm{x}}$ é o número de vezes que a tarefa $\mathrm{x}$ ocorre; $M_{y}$ é a quantidade total de material y na construção; $P_{x, y}$ é a porcentagem de $M_{y}$ substituído devido à tarefa $x$.

Foi considerado a vida útil da edificação $(S)$ como sendo de 50 anos, conforme a ABNT NBR 15575 (ABNT, 2013). Como foi realizado uma análise de sensibilidade para saber qual a vida útil mínima do revestimento de terra, a frequência da tarefa (Fx) variou de 1 ano a 50 anos. O parâmetro Pxy foi considerado igual a $100 \%$, ou seja, todo o revestimento é substituído.

Para as argamassas convencionais de cimento e cal adotou-se que não haverá reposição das mesmas (mesma vida útil da edificação de 50 anos). Embora as argamassas de terra utilizadas nas faces internas e externas da fachada sejam diferentes, foi considerado que ambas são substituídas durante a reposição do revestimento e enviadas para aterro de resíduos inertes. Foi contabilizado que o revestimento de tinta acrílica também é substituído nos revestimentos com argamassa de terra, considerando o dataset Acrylic varnish, without water, in $87.5 \%$ solution state $\{G L O\}$ do Ecoinvent v. 3.3. Outras atividades como limpeza não foram consideradas.
Brás e Faria (2017) propuseram uma equação para a estimativa da vida útil das argamassas à base de cimento e cal hidráulica, para estudos de ACV, com base na perda do ligante da argamassa devido ao efeito de lixiviação. No entanto, decidiu-se não aplicar o modelo, tendo em vista que as argamassas estudadas no presente estudo são à base de terra e algumas delas foram confeccionadas com cal hidratada.

\section{RESULTADOS E DISCUSSÕES}

\subsection{Avaliação das argamassas}

Nas Figuras 3, 4, 5 e 6 são apresentados os potenciais impactos ambientais das diferentes argamassas avaliadas $\left(\mathrm{em} \mathrm{m}^{3}\right)$, sem considerar a unidade funcional.

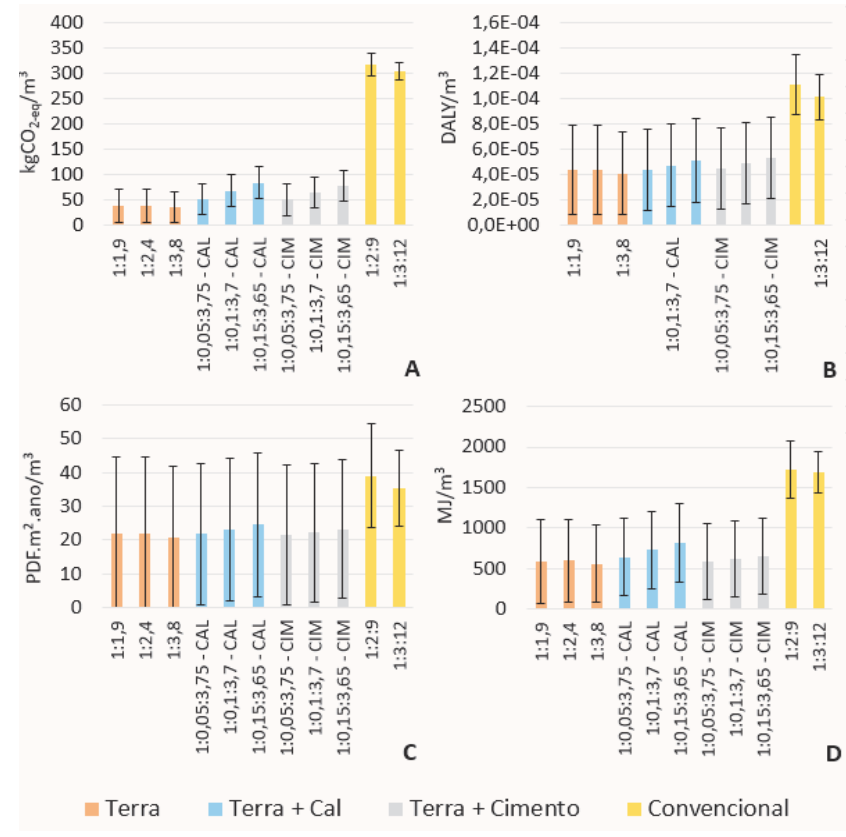

CAL - Argamassas de terra com cal hidratada. CIM - Argamassas de terra com cimento Portland. Figura 03 - Comparação dos potenciais impactos ambientais das argamassas avaliadas $\left(\mathrm{em} \mathrm{m}^{3}\right.$ ). (A) Mudanças Climáticas. (B) Saúde Humana. (C) Qualidade do Ecossistema. (D) Depleção de Recursos. Fonte: Autores (2020).

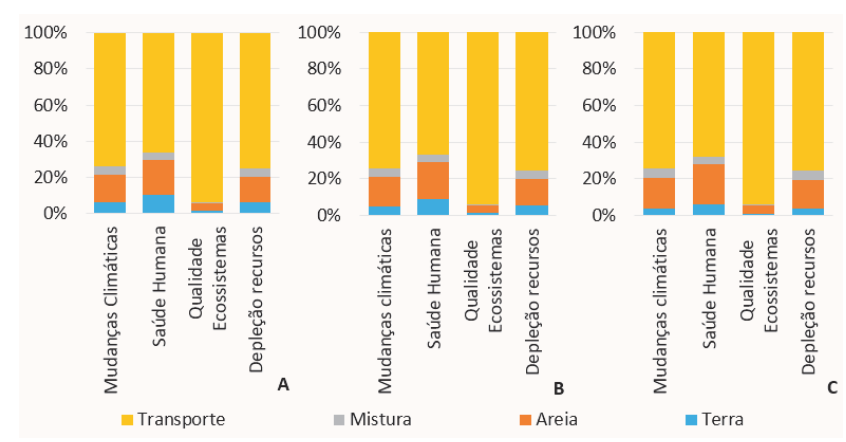

Figura 04 - Argamassa de terra sem ligante químico. (A) Traço 1:0,05:3,75. (B) Traço 1:0,1:3,7. (C) Traço 1:0,15:3,65. As barras de erros representam a variação nas distâncias de transporte utilizados para a produção das argamassas.

Fonte: Autores (2020). 


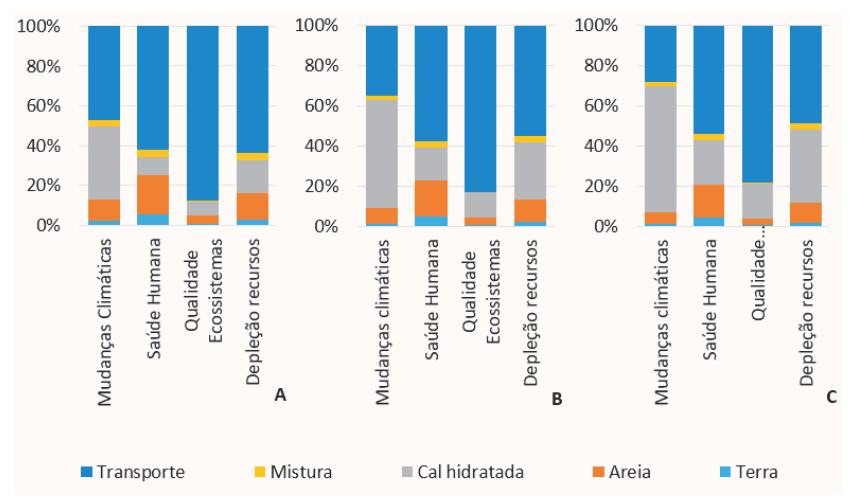

Figura 05 - Argamassa de terra com cal hidratada. (A) Traço 1:0,05:3,75. (B) Traço 1:0,1:3,7. (C) Traço 1:0,15:3,65.

Fonte: Autores (2020).

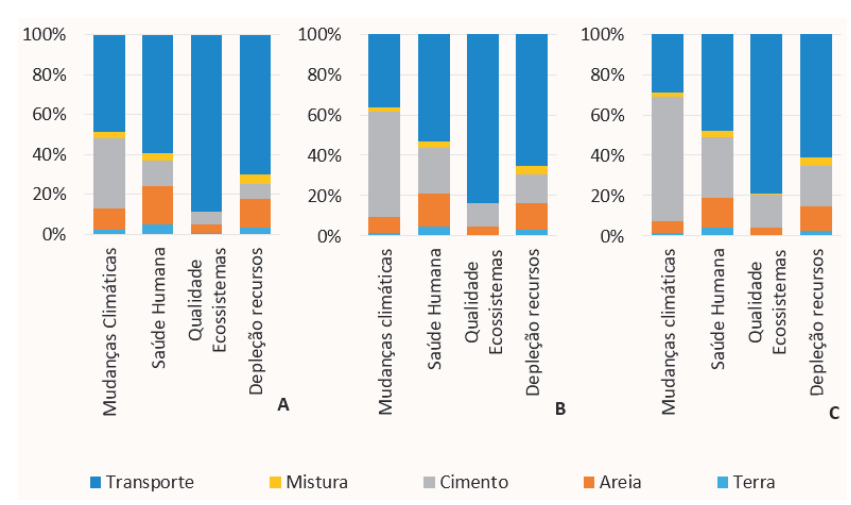

Figura 06 - Argamassa de terra com cimento, traços em massa. (A) Traço 1:0,05:3,75. (B) Traço 1:0,1:3,7. (C) Traço 1:0,15:3,65.

Fonte: Autores (2020).

Para as argamassas de terra e areia, a areia foi o material mais impactante. A sua produção a partir do processo de britagem gera um maior consumo de diesel de acordo com os dados utilizados, quando comparado com a extração da argila (material considerado no inventário). Vale ressaltar que o teor de areia no traço da argamassa vai depender do tipo de terra utilizada (em função da quantidade e natureza de argilominerais). É uma prática comum, durante a execução de revestimentos de terra, a adição de areia para diminuir o efeito de retração plástica e retração por secagem, que ocorrem principalmente em terras muito argilosas. A redução da fissuração associada à retração é uma medida muito importante quando se considera a questão da durabilidade e da vida útil, tendo em vista que as fissuras abrem caminho para ingresso de água e outros agentes deletérios.

Para as argamassas de terra estabilizada, os estabilizantes químicos (cal e cimento) foram os materiais mais impactantes para todas as categorias de impacto avaliadas. Arrigoni et al. (2017) e Martins et al. (2018), que estudaram terra estabilizada comprimida e terra autoadensável com fibras de sisal, respectivamente, verificaram que o estabilizante químico (cimento) foi o insumo mais impactante, corroborando os resultados encontrados no presente trabalho. Fernandes et al. (2019) também estudaram o sistema de terra comprimida estabilizada com cal e concluíram que a cal é um dos materiais mais impactantes. Isso se dá pelo fato de serem materiais industriais de elevada intensidade energética e não estarem tão próximos aos locais de uso, como a terra (na maioria dos casos).

Quando são avaliadas distâncias intermediárias e máximas, o transporte apresentou maior participação nas etapas avaliadas para as argamassas de terra. Esse fato está relacionado à pequena contribuição de impactos para a extração de terra e pelo fato de o processo de mistura das argamassas (que normalmente consome energia elétrica) apresentar uma participação que pode ser desprezada. Em alguns casos, como construções mais simples e locais com menor quantidade de recursos e condições de logística, a mistura pode ser realizada de forma manual, o que resulta em impactos ambientais nulos nessa etapa.

\subsection{Avaliação da vedação vertical}

$\mathrm{Na}$ Figura 7, são apresentados os potenciais impactos ambientais dos revestimentos avaliados, considerando as etapas produção dos materiais, transporte e execução do revestimento (A1-A5) e fim de vida do revestimento (C1C4) e a unidade funcional definida (em $\mathrm{m}^{2}$ ).

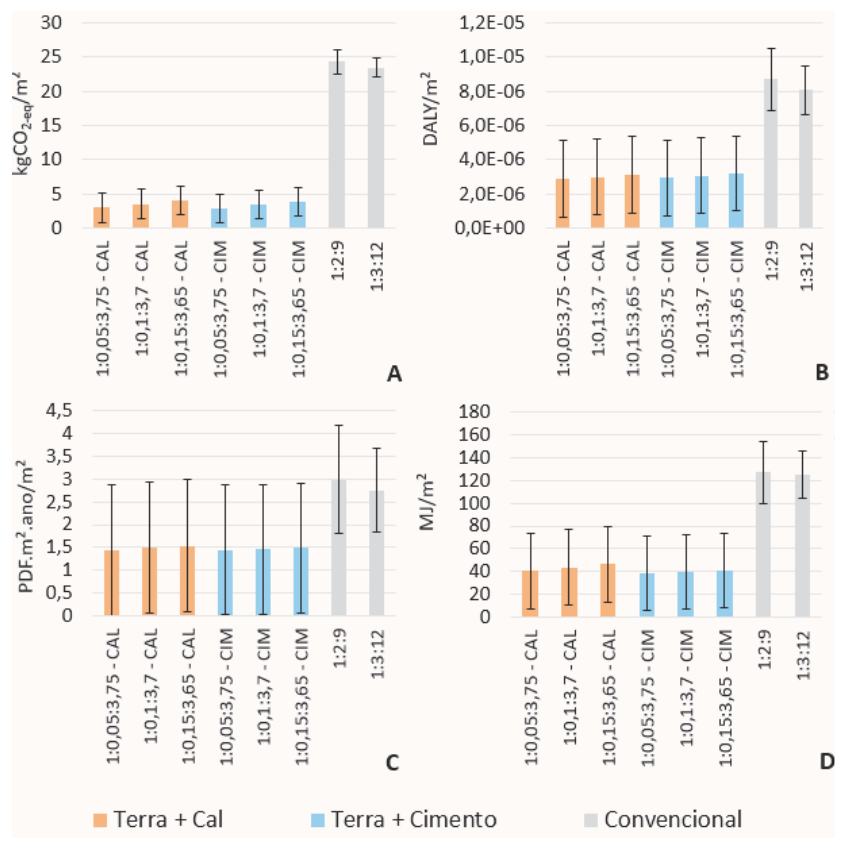

CAL - Argamassas de terra com cal hidratada. CIM - Argamassas de terra com cimento Portland.

Figura 07 - Comparação dos potenciais impactos ambientais dos revestimentos avaliados (em $\mathrm{m}^{2}$ ). (A) Mudanças Climáticas. (B) Saúde Humana. (C) Qualidade do Ecossistema. (D) Depleção de Recursos.

Fonte: Autores (2020). 
Os revestimentos de terra quando comparados com as argamassas convencionais apresentam menores potenciais impactos ambientais, principalmente para as categorias de Mudanças Climáticas, Saúde Humana e Depleção de Recursos, chegando a diferenças de $80 \%$, para a primeira categoria.

A maior diferença na categoria de Mudanças Climáticas se deve ao fato de grande parte do impacto das argamassas convencionais estar relacionado ao processo de calcinação do cimento Portland e da cal hidratada, que libera CO2 na reação química. Caldas e Toledo Filho (2018) verificaram que esses materiais em conjunto são responsáveis por mais de $80 \%$ do impacto para essa categoria de impacto. Em contrapartida, o baixo teor de ligantes químicos nas argamassas de terra faz esse impacto diminuir.

A variação nas distâncias de transporte dos insumos constituiu um fator bastante importante, principalmente para os revestimentos de terra, em especial para a categoria de Qualidade do Ecossistema, que possui uma grande influência da queima de diesel. Caldas et al. (2020a) também verificaram uma grande participação da etapa de transporte para essa categoria de dano, quando são avaliadas edificações de container.

Dentre as etapas do ciclo de vida consideradas, a produção dos insumos (A1-A3) e transporte (A4) foram os mais impactantes, somando mais de $90 \%$. As etapas de mistura (A5) e fim de vida (C1-C4) tiveram participação pouco expressiva, sendo que juntas somaram menos de $10 \%$ dos impactos. Isso aconteceu para as quatro categorias avaliadas. Esses resultados se justificam porque nessas etapas ocorre somente consumo de energia elétrica para a mistura e consumo de diesel para o transporte (sendo consideradas pequenas distâncias, de 20 a $60 \mathrm{~km}$ ), e a destinação final é o processo de aterramento.

\subsection{Análise de sensibilidade da vida útil e dis- tâncias de transporte}

Nas Figuras 8, 9, 10 e 11, são apresentados cenários quando são considerados os diferentes valores de vida útil e distâncias de transporte (mínimas e máximas) das argamassas de terra para os danos avaliados. Nas Tabelas 2 e 3, são apresentados os valores de vida útil mínimos necessários para que as argamassas de terra sejam ambientalmente mais vantajosas (para as quatro categorias avaliadas) que as convencionais.

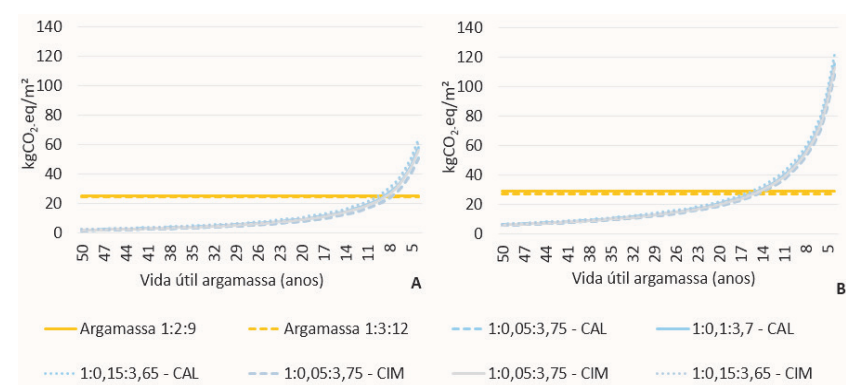

CAL-Argamassas de terra com cal hidratada. CIM - Argamassas de terra com cimento Portland. Figura 08 - Avaliação da vida útil das argamassas de terra para a categoria de Mudanças Climáticas. (A) Distâncias mínimas. (B) Distâncias máximas Fonte: Autores (2020).

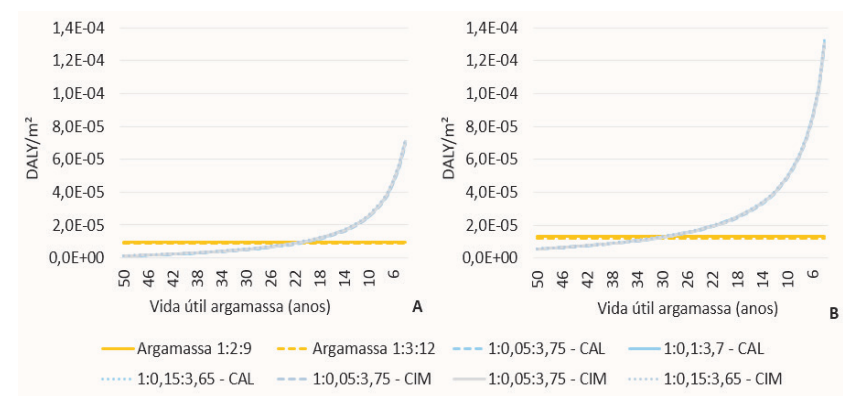

CAL - Argamassas de terra com cal hidratada. CIM - Argamassas de terra com cimento Portland.

Figura 09 - Avaliação da vida útil das argamassas de terra para a categoria de Saúde Humana. (A) Distâncias mínimas. (B) Distâncias máximas.

Fonte: Autores (2020).
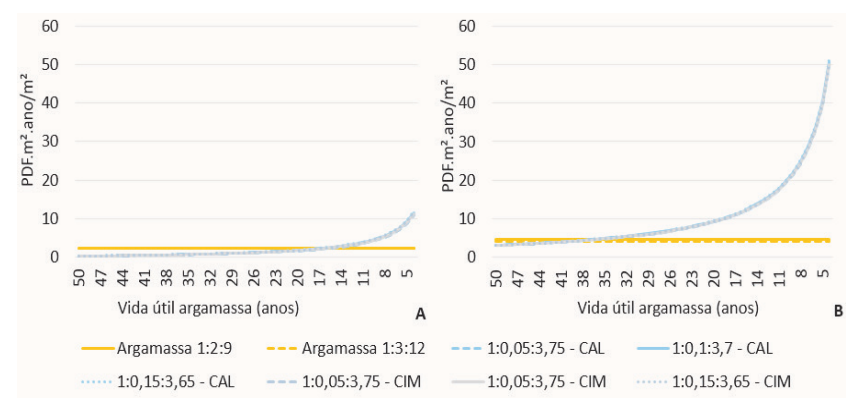

CAL-Argamassas de terra com cal hidratada. CIM - Argamassas de terra com cimento Portland.

Figura 10 - Avaliação da vida útil das argamassas de terra para a categoria de Qualidade do Ecossistema. (A) Distâncias mínimas. (B) Distâncias máximas.

Fonte: Autores (2020).
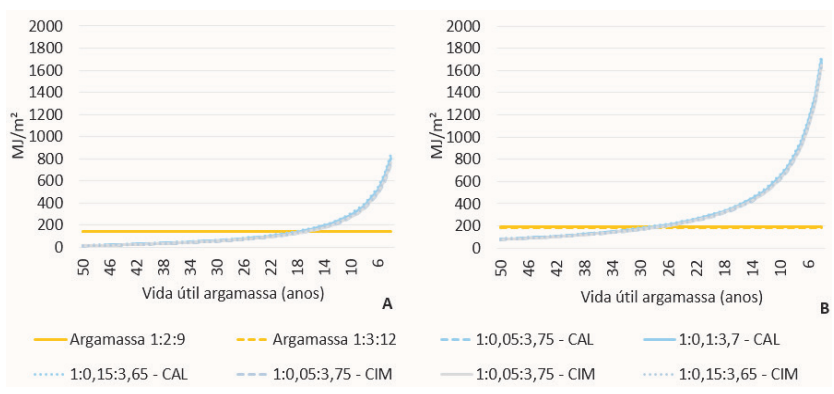

CAL - Argamassas de terra com cal hidratada. CIM - Argamassas de terra com cimento Portland.

Figura 11 - Avaliação da vida útil das argamassas de terra para a categoria de Depleção de Recursos. (A) Distâncias mínimas. (B) Distâncias máximas. Fonte: Autores (2020). 


\begin{tabular}{|l|l|l|l|}
\hline $\begin{array}{l}\text { Categorias } \\
\text { de impacto }\end{array}$ & $\begin{array}{l}\mathbf{1 : 0 , 0 5 : 3 , 7 5} \\
\text { CIM }\end{array}$ & $\mathbf{1 : 0 , 1 : 3 , 7 ~ C I M}$ & $\begin{array}{l}\mathbf{1 : 0 , 1 5 : 3 , 6 5} \\
\text { CIM }\end{array}$ \\
\hline $\begin{array}{l}\text { Mudanças } \\
\text { climáticas - Min }\end{array}$ & 8 & 8 & 8 \\
\hline $\begin{array}{l}\text { Mudanças } \\
\text { climáticas - Max }\end{array}$ & 15 & 15 & 16 \\
\hline $\begin{array}{l}\text { Saúde hu- } \\
\text { mana - Min }\end{array}$ & 21 & 21 & 22 \\
\hline $\begin{array}{l}\text { Saúde huma- } \\
\text { na - Max }\end{array}$ & 29 & 29 & 30 \\
\hline $\begin{array}{l}\text { Qualidade ecos- } \\
\text { sistema - Min }\end{array}$ & 16 & 16 & 17 \\
\hline $\begin{array}{l}\text { Qualidade ecos- } \\
\text { sistema - Max }\end{array}$ & 39 & 40 & 40 \\
\hline $\begin{array}{l}\text { Depleção de } \\
\text { recursos - Min }\end{array}$ & 16 & 16 & 17 \\
\hline $\begin{array}{l}\text { Depleção de } \\
\text { recursos - Max }\end{array}$ & 27 & 27 & 28 \\
\hline
\end{tabular}

Verde - menor valor de vida útil mínima do revestimento de terra. Vermelho - maior valor de vida útil mínima do revestimento de terra.

Tabela 02 - Valores de vida útil mínimas necessárias para que o revestimento de terra seja mais vantajoso que o revestimento argamassado convencional contemplando os cenários de transporte (mínimo - Min e máximo - Max).

Fonte: Autores (2020).

\begin{tabular}{|l|l|l|l|}
\hline $\begin{array}{l}\text { Categorias } \\
\text { de impacto }\end{array}$ & $\begin{array}{l}\mathbf{1 : 0 , 0 5 : 3 , 7 5} \\
\text { CAL }\end{array}$ & $\mathbf{1 : 0 , 1 : 3 , 7 ~ C A L ~}$ & $\begin{array}{l}\mathbf{1 : 0 , 1 5 : 3 , 6 5} \\
\text { CAL }\end{array}$ \\
\hline $\begin{array}{l}\text { Mudanças } \\
\text { climáticas - Min }\end{array}$ & 8 & 9 & 9 \\
\hline $\begin{array}{l}\text { Mudanças } \\
\text { climáticas - Max }\end{array}$ & 15 & 16 & 16 \\
\hline $\begin{array}{l}\text { Saúde hu- } \\
\text { mana - Min }\end{array}$ & 21 & 21 & 22 \\
\hline $\begin{array}{l}\text { Saúde huma- } \\
\text { na - Max }\end{array}$ & 29 & 29 & 30 \\
\hline $\begin{array}{l}\text { Qualidade ecos- } \\
\text { sistema - Min }\end{array}$ & 16 & 16 & 17 \\
\hline $\begin{array}{l}\text { Qualidade ecos- } \\
\text { sistema - Max }\end{array}$ & 39 & 40 & 40 \\
\hline $\begin{array}{l}\text { Depleção de } \\
\text { recursos - Min }\end{array}$ & 17 & 17 & 18 \\
\hline $\begin{array}{l}\text { Depleção de } \\
\text { recursos - Max }\end{array}$ & 28 & 28 & 29 \\
\hline
\end{tabular}

Verde - menor valor de vida útil mínima do revestimento de terra. Vermelho - maior valor de vida útil mínima do revestimento de terra.

Tabela 03 - Valores de vida útil mínimas necessárias para que o revestimento de terra seja mais vantajoso que o revestimento argamassado convencional contemplando os cenários de transporte (mínimo - Min e máximo - Max).

Fonte: Autores (2020).

Para os cenários envolvendo maiores distâncias de transporte dos materiais, os valores de vida útil dos revestimentos de terra precisam ser maiores caso se deseje maior competitividade em relação aos revestimentos convencionais. Principalmente quando se considera na avaliação o transporte dos novos materiais e do revestimento antigo incluindo sua destinação final.
Para a categoria de Mudanças Climáticas, em um cenário de menores distâncias de transporte dos insumos, o revestimento de terra precisaria ter pelo menos uma vida útil de 8 anos. Por outro lado, para o cenário de maiores distâncias, a vida útil precisaria ser de, pelo menos, 16 anos, considerando as combinações mais impactantes (traços 1: 0,05: 3,65).

Para as outras categorias de dano, esse intervalo foi de 21 a 30 anos para Saúde Humana, 16 a 40 anos para a Qualidade do Ecossistema e 17 a 29 anos para a Depleção de Recursos. Portanto, evidencia-se a importância da elaboração de projetos que aumentem a vida útil dos revestimentos de terra, incorporando consequentemente detalhes construtivos tais como proteção da base, beirais maiores e proteções laterais (como por exemplo brises), objetivando maximizar o potencial dos ganhos ambientais.

Brás e Faria (2017) verificaram a importância de considerar a vida útil de revestimentos à base de cimento e cal, mostrando que um maior impacto ambiental de produção (no caso desses revestimentos o potencial de aquecimento global) pode ser compensado com a ampliação da vida útil ao longo do ciclo de vida da edificação. Elas observaram que argamassas com maior teor de cimento na composição, embora tenham um maior impacto ambiental inicial, possuem um menor impacto global, pois a vida útil é aumentada devido à diminuição do fenômeno de lixiviação.

A categoria de Qualidade do Ecossistema, seguida da Saúde Humana e Depleção de Recursos, foram as mais influenciadas pela distância de transporte da terra, aumentando consideravelmente a vida útil mínima necessária. Isso se dá pelo fato dessas categorias de dano serem sensíveis à queima de diesel que ocorre durante o transporte.

A categoria de Depleção de Recursos foi a mais influenciada pela tinta, que também será reposta quando o revestimento argamassado de terra for substituído.

\subsection{Análise de sensibilidade do teor de estabili- zante e distância de transporte da terra}

Ainda em relação ao transporte, verifica-se que a terra em si é o material que exerce maior impacto, fato este também verificado por Martins et al. (2018) e Ben-Alon et al. (2019), corroborando, de forma quantitativa, para a recomendação de usar terra local, isto é, quando existir terra em quantidade e qualidade disponível próxima ao canteiro de obras. Como o estabilizante químico é o material de maior impacto, talvez seja mais interessante obter uma terra mais distante, mas que requeira um menor teor de estabilizante.

Pensando nisso foi realizada uma análise de sensibilidade, onde foram considerados teores de cal de 2,5\%; 5\%; 10\% e $15 \%$ (em relação à massa de terra), sendo considerado para o 
caso de $15 \%$ um solo local com distância de $5 \mathrm{~km}$. E para os teores de 2,5\%; $5 \%$ e $10 \%$ foi verificado até quais valores de distâncias a terra utilizada na mistura das argamassas pode ser transportada. Nas Figuras 12 e 13, são apresentados os resultados quando a análise de sensibilidade é realizada considerando diferentes teores de estabilizantes químicos, cal e cimento, respectivamente, e distância de transporte da terra utilizada.
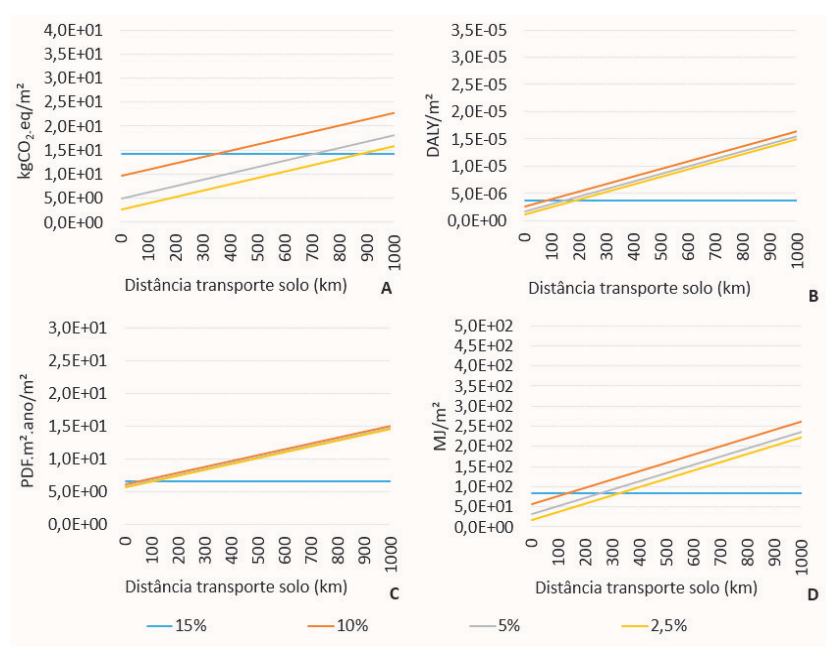

Figura 12 - Análise de sensibilidade entre teor de cal e distância de transporte do solo nos impactos ambientais do revestimento de terra (em $\mathrm{m}^{2}$ ). (A) Mudanças Climáticas. (B) Saúde Humana. (C) Qualidade do Ecossistema. (D) Depleção de Recursos.

Fonte: Autores (2020).

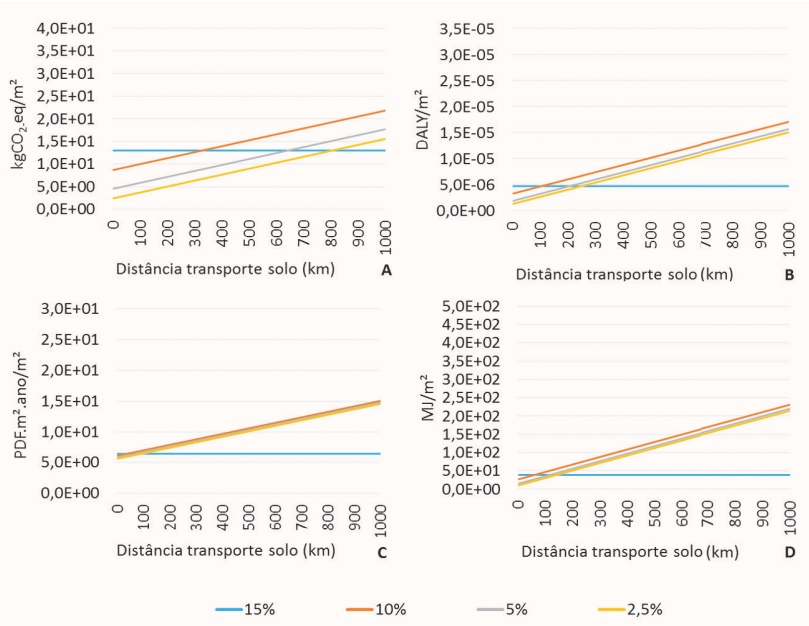

Figura 13 - Análise de sensibilidade entre teor de cimento e distância de transporte do solo nos impactos ambientais do revestimento de terra $\left(\mathrm{em} \mathrm{m}^{2}\right.$ ). (A) Mudanças Climáticas. (B) Saúde Humana. (C) Qualidade do Ecossistema. (D) Depleção de Recursos.

Fonte: Autores (2020).

Com base nos resultados verifica-se que para o dano de Mudanças Climáticas é mais vantajoso utilizar solos de locais mais distantes, podendo chegar a uma distância superior a $850 \mathrm{~km}$ (para cal) e $800 \mathrm{~km}$ (para o cimento), caso seja necessário um teor de estabilizante de 2,5\% (na hipótese de os solos serem de melhor qualidade e precisarem de um menor teor de estabilizante).
Por outro lado, para as outras categorias de dano, principalmente para Qualidade dos Ecossistemas, o uso de terra de locais mais distantes não é uma alternativa tão vantajosa, com um limite estimado de no máximo 100 km, para ambos os ligantes, devido ao impacto da queima do diesel para essa categoria, que é superior aos impactos dos ligantes químicos.

Comparando os dois cenários com ligantes químicos diferentes, a maior diferença ocorre para a categoria de Depleção de Recursos. Para o caso da cal é mais vantajoso utilizar solos de melhor qualidade, porém mais distantes, com distância até 300 km, do que aumentar seu teor na mistura. Isso ocorre porque a produção de cal tem um impacto superior ao dobro da produção de cimento para essa categoria de dano.

Esses achados são importantes quando se pensa em uma especificação ambientalmente mais responsável de revestimentos de terra, tendo em vista que a terra é um material natural e não homogêneo e pode ter sua disponibilidade comprometida, tanto em quantidade (por exemplo em locais muito adensados (CORDEIRO et al., 2019), quanto em qualidade. Pensando em um futuro próximo, em que são incentivadas cidades cada vez mais compactas, do ponto de vista da sustentabilidade e economia de recursos, como aponta Leite (2010), é de se esperar que o uso de terra local para centros urbanos seja cada vez mais difícil. Por outro lado, nos centros urbanos muito adensados pode existir a oferta de terra de obras de terraplanagem e obras de escavação de pavimentos subterrâneos, pois quanto maior o adensamento maior tende a ser o aproveitamento dos níveis subterrâneos.

Essa discussão mostra a importância de se avaliar diferentes alternativas, do ponto de vista ambiental, para a produção de revestimentos de terra mais adequados e mais duráveis.

Esses resultados também evidenciam que dependendo do impacto ambiental avaliado as diretrizes de projeto e especificação podem ser completamente diferentes. Dessa forma, pensando em uma especificação de menor impacto ambiental, é importante definir primeiramente qual o impacto que se pretende reduzir, em seguida pensar nas estratégias e possibilidades disponíveis e por fim compatibilizar as variáveis visando à obtenção de uma solução particularizada otimizada.

\section{CONCLUSÕES}

Embora os revestimentos de terra apresentem menores potenciais impactos ambientais que os convencionais, uma vida útil menor pode mudar completamente a avaliação dos resultados finais. Por outro lado, se eles tiverem 
uma vida útil similar à dos revestimentos convencionais, é possível obter consideráveis ganhos ambientais, por exemplo, podendo chegar a mais de $80 \%$ de redução para o impacto de Mudanças Climáticas. Verificou-se que a disponibilidade local de solo, o tipo e teor de estabilizante químico e a vida útil são fatores importantes para uma especificação ambiental de argamassas de terra.

Dependendo da qualidade do solo local, em alguns casos, como para o impacto de Mudanças Climáticas e Depleção de Recursos, é mais vantajoso utilizar solos de distâncias maiores se eles necessitarem de um menor teor de estabilizante químico. Por outro lado, para impactos na Saúde Humana e Qualidade do Ecossistema, o uso de solos locais constituiu um item mais importante que o aumento do teor do estabilizante. Nessa ótica, cada caso e categoria de impacto devem ser avaliados de forma pontual.

Esse estudo contribui para definição de parâmetros de projeto importantes para a formulação de revestimentos de terra, com base em um melhor desempenho e sustentabilidade ambiental. Esses achados podem auxiliar o desenvolvimento de uma norma sobre especificação de argamassa de terra para a realidade brasileira com base em critérios ambientais e vida útil, corroborando os requisitos da NBR 15575 (ABNT, 2013).

Para estudos futuros pretende-se explorar como outros requisitos de desempenho, como higrotérmico e acústico, podem influenciar nos impactos ambientais do ciclo de vida desses revestimentos, como também incluir a avaliação de outros materiais de revestimento, por exemplo, cerâmica e rochas ornamentais. Pretende-se também correlacionar modelos de vida útil mais precisos para essas argamassas, com base em resultados experimentais, como foi apresentado por Brás e Faria (2017).

\section{AGRADECIMENTOS}

Os autores gostariam de agradecer o apoio e concessão de bolsas de doutorado pelo Conselho Nacional de Desenvolvimento Científico e Tecnológico (CNPq).

\section{REFERÊNCIAS}

ANAND, C. K. and AMOR, B. Recent developments, future challenges and new research directions in LCA of buildings: A critical review. Renewable and Sustainable Energy Reviews, January 2017, vol. 67, $\mathrm{n}^{\circ} 1$, p. 408-416.

ARRIGONI, A.; BECKETT, C.; CIANCIO, D.; DOTELLI, G. Life cycle analysis of environmental impact vs. durability of stabilized rammed earth. Construction and Building Materials, v. 142, n. 1, p.128-136. 2017.
ASSOCIAÇÃO BRASILEIRA DE NORMAS TÉCNICAS. ABNT. NBR 13276: Argamassa para assentamento e revestimento de paredes e tetos - Preparo da mistura e determinação do índice de consistência. Rio de Janeiro, 2005.

ASSOCIAÇÃO BRASILEIRA DE NORMAS TÉCNICAS. ABNT. NBR 14040: Gestão Ambiental - Avaliação do Ciclo de vida. Rio de Janeiro, 2009.

ASSOCIAÇÃO BRASILEIRA DE NORMAS TÉCNICAS. ABNT. NBR 15575: Edificações Habitacionais Desempenho. Rio de Janeiro, 2013.

ASSOCIAÇÃO BRASILEIRA DE NORMAS TÉCNICAS. ABNT.NBR 16697: Cimento Portland - Requisitos. Rio de Janeiro, 2018.

ASSOCIAÇÃO BRASILEIRA DE NORMAS TÉCNICAS. ABNT.NBR 7175: Cal hidratada para argamassas Requisitos. Rio de Janeiro, 2003.

ATELIER O`R, Site oficial. 2019 Disponível em: <> http:// atelieroreilly.com.br/?p=5079. Consulta em setembro de 2019.

BEN-ALON, A.; LOFTNESS, V.; HARRIES, V. K.; DIPIETRO, G.; HAMEEN, E. C. Cradle to site Life Cycle Assessment (LCA) of natural vs conventional building materials: A case study on cob earthen material. Building and Environment. 160, p. 1-10., 2019.

BOWICK, M. Brock Commons Tallwood House, University of British Columbia An Environmental Building Declaration According to EN 15978 Standard. Athena Sustainable Materials Institute, 2018. BRÁS, A. and FARIA, P., November 2017. Effectiveness of mortars composition on the embodied carbon long-term impact. Energy and Buildings, v. 154, p. 523528, 2017.

CALDAS, L. R.; ABREU-HARBICH, L. V.; HORA, K. E. R. Avaliação ambiental de alternativas construtivas de um edifício container. PARC Pesquisa Em Arquitetura E Construção, v. 11, e020008, 2020a.

CALDAS, L. R.; CARVALHO, M. T. M.; TOLEDO FILHO, R. D. Avaliação de estratégias para mitigação dos impactos ambientais de revestimentos argamassados no Brasil. Ambiente Construído, v. 20, n.3, p. 343-362, 2020b.

CALDAS, L. R.; TOLEDO FILHO, Romildo Dias, Avaliação do Ciclo de Vida de materiais cimentícios utilizados no Brasil: estudo para argamassas, graute e bloco de concreto. LALCA - Revista Latino-amer. em Aval. do Ciclo de Vida, Brasília, v. 2, n. 2, p. 34-61, 2018. CARASEK, H. Argamassas. In: ISAIA, G.C. (Ed.). Materiais de Construção Civil e Princípios de Ciência e 
Engenharia de Materiais. São Paulo: IBRACON, $2^{a}$ edição, volume 2, Capítulo 28, p. 893-944, 2010.

CEN (1998) - EN 1015-3: Methods of test for mortar for masonry - Part 3: Determination of consistence of fresh mortar (by flow table), Brussels.

CEN (1999) - EN 1015-11: Methods of test for mortar for masonry - Part 11: Determination of flexural and compressive strength of hardened mortar, Brussels.

CEN (2012) - EN 15804: Sustainability of construction works: environmental product

declarations: core rules for the product category of construction products. Brussels.

CEN (2016) - EN 1015-12: Methods of test for mortar for masonry. Part 12: Determination of adhesive strength of hardened rendering and plastering mortars on substrates, Brussels.

CHRISTOFOROU, E.; KYLILI A, FOKAIDES PA, IOANNOU I, Cradle to site life cycle assessment (LCA) of adobe as a building element, Journal of Cleaner Production, v. 112, n. 20, p. 443-452, 2016.

CORDEIRO, C. C. M. et al. Construções vernáculas em terra: perspectiva histórica, técnica e contemporânea da taipa de mão. PARC Pesquisa em Arquitetura e Construção, Campinas, SP, v. 10, p. e01906, 2019.

DAMME, H.; HOUBEN, H. Earth concrete. Stabilization revisited. Cement and Concrete Research, v. 114, p. 90-102, 2018.

DANSO, H.; MANU, D. Influence of coconut fibres and lime on the properties of soil-cement mortar. Construction and Building Materials, v.12, p. 1-12, 2020.

EIRES, R.; CARDOSO, C.; CAMÕES A. Argamassas de terra e cal reforçadas com fibras naturais. Anais... Primeiro Congresso Luso-Brasileiro de Materiais de Construção Sustentáveis, Portugal, 2014

EUROPEAN COMMITTEE FOR STANDARDIZATION. CEN EN 15804: sustainability of construction works: environmental product declarations: core rules for the product category of construction products. Brussels, 2012.

FARIA, P. Argamassas de cal e terra: características e possibilidades de aplicação. Ambiente Construído, v. 18, n. 4, p. 49-62, 2018.

FARIA, P. Argamassas de terra e cal - características e campos de aplicação, Anais...V Jornadas Fiscal, Fórum Ibérico de Cal, p. 277 - 286, 2016

FARIA, P.; HENRIQUES, F.; RATO, V. Comparative Evaluation of Aerial Lime Mortars for Architectural Conservation. Journal of Cultural Heritage, v. 9, n. 3, p. 338-346, 2008.

FERNANDES, J.; PEIXOTO, M.; MATEUS, R.; GERVÁSIO, H. Life cycle analysis of environmental impacts of earthen materials in the Portuguese context: Rammed earth and compressed earth blocks, Journal of Cleaner Production, v. 241, n.20, 82-86, 2019.

GARCÍA-VERA, V.E.; LANZON, M. Physical-chemical study, characterization and use of image analysis to assess the durability of earthen plasters exposed to rain water and acid rain, Construction and Building Materials, v.187, p. 708-717, 2018.

GOMES, M. I.; FARIA, P.; GONÇALVES, T. D. Earth-based mortars for repair and protection of rammed earth walls. Stabilization with mineral binders and fibers. Journal of Cleaner Production, v. 172, p.2401-2414, 2018.

HEMA, C.M.; MOESEKE, G.V.; EVRAD, A.; COURARD, L.; MESSAN, A. Vernacular housing practices in Burkina Faso: representative models of construction in Ouagadougou and walls hygrothermal efficiency.

Energy Procedia, v. 122, p. 535-540, 2017.

KULSHRESHTHA, Y.; MOTA, N.J.A.; JAGADISH, K.S.; BREDENOORD, J.; VARDON, P.J.; VAN LOOSDRECHT, M.C.M.; JONKERS, H.M. The potential and current status of earthen material for low-cost housing in rural India. Construction and Building Materials, v.247, pp. 1-14, 2020.

LEITE, C.. Cidades sustentáveis? Desafios e oportunidades. ComCiência, Campinas, n. 118, 2010.

MARCELINO-SADABAA, S.; KINUTHIA, J.; OTI, J. E.; SECO, A. 2017. Challenges in Life Cycle Assessment (LCA) of stabilized clay-based construction materials. Applied Clay Science, v. 144, p. 121-130, 2017.

MARTINS, A. P. S.; CALDAS, L. R, PAIVA, R. L. M.; TOLEDO FILHO, R. D. Avaliação do ciclo de vida de compósitos solo-cimento-fibras de sisal considerando diferentes distâncias de transporte. VII Congresso de Arquitetura e Construção com Terra no Brasil. In: Anais...Rio de Janeiro, 2018.

MELIÀ, P.; RUGGIERI, G.; SABBADINI, S.; DOTELLI, D. Environmental impacts of natural and conventional building materials: a case study on earth plasters. Journal of Cleaner Production, v. 80, p. 179 - 186, 2014.

MIRANDA, A.; YUBA, A. N.. Comparação de impactos ambientais de sistemas construtivos de paredes utilizando avaliação do ciclo de vida modular. In: Anais... ENTAC, 16., 2016, São Paulo. Anais[...] Porto Alegre: ANTAC, 2016. 
NGOWI, A.B. Improving the traditional earth construction: a case study of Botswana. Construction and Building Materials, v.11, n.1, p. 1-7, 1997.

OUELLET-PLAMONDON, C. M.; HABERT, G. SelfCompacted Clay based Concrete (SCCC): proof-of-concept. Journal of Cleaner Production, v. 117, p. 160168, 2016.

PERROT, A.; RANGEARD, D.; MENASRIA, F.; GUIHÉNEUF, $S$. Strategies for optimizing the mechanical strengths of raw earth-based mortars. Construction and Building Materials, v. 167, p. 496 - 504, 2018.

QUAGLIARINI, E.; LENCI, S. The influence of natural stabilizers and natural fibres on the mechanical properties of ancient Roman adobe bricks. Journal of Cultural Heritage, v.11, p. 309 - 314, 2010.

SANTOS, T.; FARIA, P.; SILVA, V. Can an earth plaster be efficient when applied on different masonries? Journal of Building Engineering, v.23, pp. 314-323, 2019.

SANTOS, T.; SILVA, V.; FARIA, P. Caracterização de Argamassa Pré-Dosada de Terra, I Simpósio de Argamassas e Soluções Térmicas de Revestimento, 2014

SERRANO, S.; BARRENECHE, C; RINCÓN, L.; BOER,

D.; CABEZA, L. F. Optimization of three new compositions of stabilized rammed earth incorporating PCM: Thermal properties characterization and LCA, Construction and Building Materials, v.47, p. 872 878, 2013.

SINAPI. Cadernos Técnicos de Composições para Argamassas e Grautes. Lote 1, Caixa Econômica Federal, 2017.

SOUZA, D. M.; LAFONTAINE, M.; CHARRON-DOUCET, F.; CHAPPERT, B.; KICAK, K.; LIMA, L. Comparative life cycle assessment of ceramic brick, concrete brick and castin-place reinforced concrete exterior walls. Journal of Cleaner Production, v.137, n. 20, p. 70-82, jan. 2016.

TORGAL; F. P.; EIRES; R. M. G.; JALALI, S. Construção em

Terra. Guimarães: Publidisa, 2009.

UNESCO, Historic Centre of Brazil, 2019 site: http:// Www.unesco.org

VITOR, A. O.; LISBÔA, S.; LIBRELOTTO, L. I. Argamassas de revestimento com terra: finalização do protótipo Experimental em bambu da UFSC. Mix Sustentável, Florianópolis, v.6, n.1, p.29-44, 2020.

\section{AUTORES}

ORCID: https://orcid.org/0000-0002-3108-2833

LUCAS ROSSE CALDAS, Dr.| Universidade Federal do Rio de Janeiro (UFRJ)| Programa de Engenharia Civil (COPPE/PEC) | Rio de Janeiro, RJ - Brasil| Correspondência para: NUMATS/ COPPE/UFRJ -Avenida Athos da Silveira Ramos, Centro de Tecnologia, Bloco I-110, Cidade Universitária, Ilha do Fundão, Rio de Janeiro, RJ, 21945-970| E-mail: Irc@coc.ufrj.br

ORCID: https://orcid.org/0000-0001-9392-9238

RAYANE DE LIMA MOURA PAIVA, M.Sc. | Universidade Federal do Rio de Janeiro (UFRJ)| Programa de Engenharia Civil (COPPE/PEC) | Rio de Janeiro, RJ - Brasil| Correspondência para: NUMATS/COPPE/UFRJ -Avenida Athos da Silveira Ramos, Centro de Tecnologia, Bloco I-110, Cidade Universitária, Ilha do Fundão, Rio de Janeiro, RJ, 21945970| E-mail: rayane@coc.ufrj.br

\section{ORCID: https://orcid.org/0000-0001-6448-2641}

ADRIANA PAIVA DE SOUZA MARTINS, Dra. | Universidade Federal do Rio de Janeiro (UFRJ)| Programa de Engenharia Civil (COPPE/PEC) | Rio de Janeiro, RJ - Brasil| Correspondência para: NUMATS/COPPE/UFRJ -Avenida Athos da Silveira Ramos, Centro de Tecnologia, Bloco I-110, Cidade Universitária, Ilha do Fundão, Rio de Janeiro, RJ, 21945970| E-mail: adrianapsmartins@globo.com

ORCID: https://orcid.org/0000-0001-5867-4452

ROMILDO DIAS TOLEDO FILHO, Dr. | Universidade Federal do Rio de Janeiro (UFRJ)| Programa de Engenharia Civil (COPPE/PEC) | Rio de Janeiro, RJ - Brasil| Correspondência para: NUMATS/ COPPE/UFRJ -Avenida Athos da Silveira Ramos, Centro de Tecnologia, Bloco I-110, Cidade Universitária, Ilha do Fundão, Rio de Janeiro, RJ, 21945-970| E-mail: toledo@coc.ufrj.br

\section{COMO CITAR ESTE ARTIGO}

CALDAS, Lucas Rosse; PAIVA, Rayane de Lima Moura; MARTINS, Adriana Paiva de Souza; FILHO, Romildo Dias Toledo. Argamassas de Terra Versus Convencionais: Avaliação do Desempenho Ambiental Considerando o Ciclo de Vida. MIX Sustentável, [S.I.], v. 6, n. 4, p. 115-128, ago. 2020. ISSN 24473073. Disponível em:<http://www.nexos.ufsc.br/index.php/mixsustentavel>. Acesso em: dia mês. ano. doi:https://doi. org/10.29183/2447-3073.MIX2020.v6.n4.115-128.

DATA DE ENVIO: $21 / 05 / 2020$

DATA DE ACEITE: $20 / 07 / 2020$ 